\title{
Glucose regulates AMP-activated protein kinase activity and gene expression in clonal, hypothalamic neurons expressing proopiomelanocortin: additive effects of leptin or insulin
}

\author{
Fang Cai ${ }^{1}$, Armen V Gyulkhandanyan ${ }^{1}$, Michael B Wheeler ${ }^{1,2}$ and Denise D Belsham ${ }^{1,2,3,4}$ \\ Departments of ${ }^{1}$ Physiology, ${ }^{2}$ Medicine and ${ }^{3}$ Obstetrics and Gynaecology, University of Toronto, Medical Sciences Building 3247A, 1 King's College Circle, \\ Toronto, Ontario, Canada M5S 1A8 \\ ${ }^{4}$ Division of Cellular and Molecular Biology, Toronto General Hospital Research Institute, University Health Network, Toronto, Ontario, Canada M5S 1 A8 \\ (Requests for offprints should be addressed to D D Belsham at Department of Physiology, University of Toronto; Email: d.belsham@utoronto.ca)
}

\begin{abstract}
The mammalian hypothalamus comprises an array of phenotypically distinct cell types that interpret peripheral signals of energy status and, in turn, elicits an appropriate response to maintain energy homeostasis. We used a clonal representative hypothalamic cell model expressing proopiomelanocortin (POMC; N-43/5) to study changes in AMPactivated protein kinase (AMPK) activity and glucose responsiveness. We have demonstrated the presence of cellular machinery responsible for glucose sensing in the cell line, including glucokinase, glucose transporters, and appropriate ion channels. ATP-sensitive potassium channels were functional and responded to glucose. The N-43/5 POMC neurons may therefore be an appropriate cell model to study glucose-sensing mechanisms in the hypothalamus. In N-43/5
\end{abstract}

POMC neurons, increasing glucose concentrations decreased phospho-AMPK activity. As a relevant downstream effect, we found that POMC transcription increased with $2 \cdot 8$ and $16.7 \mathrm{mM}$ glucose. Upon addition of leptin, with either no glucose or with $5 \mathrm{mM}$ glucose, we found that leptin decreased AMPK activity in N-43/5 POMC neurons, but had no significant effect at $25 \mathrm{mM}$ glucose, whereas insulin decreased AMPK activity at only $5 \mathrm{mM}$ glucose. These results demonstrate that individual hypothalamic neuronal cell types, such as the POMC neuron, can have distinct responses to peripheral signals that relay energy status to the brain, and will therefore be activated uniquely to control neuroendocrine function.

Journal of Endocrinology (2007) 192, 605-614

\section{Introduction}

The hypothalamus is critical for the regulation of homeostatic processes, such as feeding and energy expenditure (Schwartz et al. 2000). Within the hypothalamus, energy homeostasis is controlled by two opposing neuronal systems, through orexigenic or anorexigenic mechanisms. These neurons are modulated by circulating hormones, nutrient-derived signals, and cytokines. Specific neurons from the hypothalamus can sense nutrient-derived signals like glucose, and respond appropriately by changing the levels of neuromodulators in the brain. Two important peripheral signals are leptin, the product of the obesity $(\mathrm{Ob})$ gene, which is secreted mainly from adipocytes, and insulin, produced mainly in the pancreas, which also signals energy status to the hypothalamus (Zhang et al. 1994, Niswender \& Schwartz 2003). Leptin and insulin modulate neurons within the arcuate nucleus and are thought to act through their specific receptors on melanocortin neurons (Niswender \& Schwartz 2003, Breen et al. 2005). The two main opposing neurons in the melanocortin system express either the orexigenic hormones, NPY and
AgRP, or the anorexigenic hormones, proopiomelanocortin (POMC) and cocaine and amphetamine-regulated transcript (CART). These neuropeptides are ultimately modulated by peripheral signals that lead to changes in signaling cascades and alteration of intracellular second messengers. These cellular changes affect gene expression and neuropeptide secretion, which in turn affects feeding behavior.

Glucose is a critical fuel necessary for the survival of brain cells, which may be why the brain itself evolved a mechanism to sense and respond to peripheral glucose changes (Burdakov et al. 2005). It is likely that the brain integrates information both locally, through neuronal glucose-sensing machinery, and from peripheral sensors. The knowledge that neurons respond to changes in glucose was generated from exquisite electrophysiological experiments, which indicated that neurons can be either inhibited or excited by extracellular glucose changes (Anand et al. 1964, Oomura et al. 1964, Routh 2002, Wang et al. 2004). The hypothalamus is a recognized brain center involved in the central control of glucose homeostasis, with the lateral, arcuate, and ventromedial 
hypothalamic regions linked to glucose sensing (Levin et al. 2004). However, how individual hypothalamic NPY or POMC neurons sense glucose levels and respond with unique neuronal signals is not yet understood due to the lack of appropriate cell models.

One important cellular energy gauge is $5^{\prime}$-AMP-activated protein kinase (AMPK; Carling 2005, Kahn et al. 2005). In general, AMPK is activated in response to low levels of ATP that results in an increase in the AMP:ATP ratio. Once activated, AMPK turns on catabolic pathways to generate ATP and turns off biosynthetic pathways requiring ATP consumption (Hardie 2004). In peripheral tissues, AMPK controls a number of metabolic processes, including glucose and lipid metabolism (Kahn et al. 2005). The activity of AMPK is acutely regulated in the hypothalamus by peripheral nutrient signals, and may therefore act as a central regulator of energy balance (Kim \& Lee 2005). AMPK activity is regulated in certain regions of the hypothalamus by indicators of nutrient status, including fasting/refeeding, leptin, insulin, glucose, fatty acids, and ghrelin (Andersson et al. 2004, Kim et al. 2004, Minokoshi et al. 2004). AMPK activity has also been shown to be modulated by ciliary neurotropic factor (Steinberg et al. 2006), or the anti-diabetic drug, metformin (Chau-Van et al. 2006), both linked to weight loss. However, the exact mechanisms of AMPK action are not well defined in the hypothalamus, and it is not yet known what specific neuropeptides linked to the control of energy homeostasis are involved in this process.

The hypothalamus is a heterogeneous population of cell types, each expressing a specific complement of peptides, receptors, and neuromodulators. Since the glucose sensing and AMPK studies to date have analyzed the entire or specific regions of the hypothalamus, it is difficult to determine exactly which cell types directly respond to peripheral signals to change AMPK activity. Since AMPK activation results in the modulation of downstream events, such as changes in neuropeptide gene expression and/or secretion ultimately affecting overall energy homeostasis, it is necessary to define the cell types involved in this process. We generated a number of clonal, immortalized hypothalamic cell lines that express neuropeptides associated with energy homeostasis. These cell models were generated by retroviral transfer of T-antigen into embryonic mouse primary hypothalamic cell cultures, with subsequent subcloning to ensure pure clonal cell lines (Belsham et al. 2004). We used these cell lines to determine the effects of peripheral signals on gene expression and secretion (Belsham et al. 2004, Cui et al. 2005, Titolo et al. 2006). Using one of these cell models expressing POMC, we demonstrate the expression of functional glucose-sensing machinery, that these cells specifically respond to glucose, and that glucose itself can regulate neuropeptide gene expression. We were also able to define regulation of AMPK activity by specific nutrient signals, including glucose, leptin, and insulin.

\section{Materials and Methods}

\section{Cell immortalization and subcloning}

Immortalized cell lines were generated as described (Belsham et al. 2004, Cui et al. 2005). Briefly, hypothalami were harvested and dissected from mice at embryonic day 15 (E15), E17, and E18. The primary cell cultures were infected with retrovirus containing the intact cDNA sequence for simian virus (SV40) large T-antigen and neomycin resistance gene, harvested from a confluent culture of $\psi 2$ cells (psitex cells) producing a replicationdefective, recombinant murine retrovirus. After $48 \mathrm{~h}$ in culture medium with the retrovirus, the cells were incubated with medium containing Geneticin (G418) with a selective concentration $(400-600 \mu \mathrm{g} / \mathrm{ml}$ for initial selection; $250 \mu \mathrm{g} / \mathrm{ml}$ for cell maintenance). Mixed populations of hypothalamic cells were further subcloned by successive dilution of the trypsinized cell populations into 96-well plates. Cell colonies were allowed to grow and then successively split into 24-well plates, then into 6-well plates, and finally into $60 \mathrm{~mm}$ plates. Each cell line was purified three to four times. The N-43 cell line was subsequently purified after the initial report, in order to be confident of clonality. In this study, N-43/5 (N-43, clone 5) was used because it expressed detectable levels of POMC (Fig. 1A).

\section{Cell culture and treatments}

Immortalized cell lines were grown in Dulbecco's modified Eagle's medium (DMEM) supplemented with 10\% FBS (Invitrogen), $20 \mathrm{mM}$ glucose, and penicillin/streptomycin and maintained at $37^{\circ} \mathrm{C}$ with $5 \% \mathrm{CO}_{2} . \mathrm{N}-43 / 5$ cells were grown overnight to $80-90 \%$ confluency in $60 \mathrm{~mm}$ dishes. Cells were starved for $2 \mathrm{~h}$ in Krebs-Ringer bicarbonate HEPES (KRBH) buffer, a minimal buffer containing no glucose, before treatments, and then replaced with $2 \cdot 8$ or $16 \cdot 7 \mathrm{mM}$ glucose added to the KRBH. Cellular RNA was harvested at 1-, 2-, 4-, 6-, and 8-h time points. At each time point, RNA from a time-matched control plate with no treatment was also harvested. For the initial AMPK studies, the medium was replaced with KRBH buffer without glucose for $1 \mathrm{~h}$ before treatment. KRBH buffer was used during treatments with $0,5,10,15$, or $25 \mathrm{mM}$ glucose individually for $30 \mathrm{~min}$. Cells were then treated with the indicated concentrations of leptin (R\&D Systems, Minneapolis, MN, USA) or insulin (Novo Nordisk Canada, Inc., Mississauga, Ontario, Canada; DIN 02024233), in combination with 0,5 , or $25 \mathrm{mM}$ glucose for $30 \mathrm{~min}$ before harvesting protein to assay AMPK activity.

\section{Reverse transcriptase PCR (RT-PCR) for screening}

Total cellular RNA was isolated by Trizol reagent, based on the guanidinium thiocyanate-phenol-chloroform extraction method, following the manufacturer's instructions 


\section{$\mathrm{N}-43 / 5$ neurons}

A

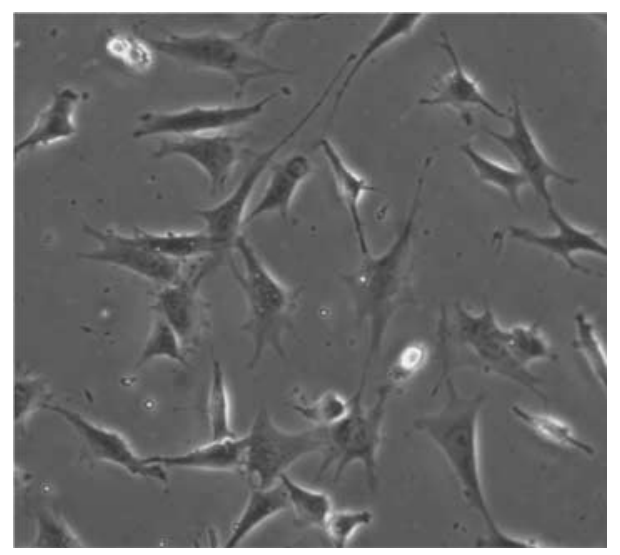

B

\begin{tabular}{|l|c|c|c|c|c|c|}
\hline & $\begin{array}{c}\text { N-29/2 } \\
\text { POMC }\end{array}$ & $\begin{array}{c}\text { N-29/4 } \\
\text { NPY }\end{array}$ & $\begin{array}{c}\text { N-38 } \\
\text { NPY }\end{array}$ & $\begin{array}{c}\text { N-42 } \\
\text { NPY }\end{array}$ & $\begin{array}{c}\text { N-43/5 } \\
\text { POMC }\end{array}$ & $\begin{array}{c}\text { N-46 } \\
\text { NPY }\end{array}$ \\
\hline Glucokinase & + & + & + & + & + & + \\
\hline Glucose transporter 1 & + & + & + & + & + & + \\
\hline Glucose transporter 2 & - & - & - & + & - & - \\
\hline Glucose transporter 3 & + & + & + & + & + & + \\
\hline Glucose transporter 4 & + & + & + & + & + & + \\
\hline
\end{tabular}

\begin{tabular}{|l|l|c|c|c|c|c|c|}
\hline & & $\begin{array}{r}\text { N-29/2 } \\
\text { POMC }\end{array}$ & $\begin{array}{r}\text { N-29/4 } \\
\text { NPY }\end{array}$ & $\begin{array}{r}\text { N-38 } \\
\text { NPY }\end{array}$ & $\begin{array}{r}\text { N-42 } \\
\text { NPY }\end{array}$ & $\begin{array}{r}\text { N-43/5 } \\
\text { POMC }\end{array}$ & $\begin{array}{c}\text { N-46 } \\
\text { NPY }\end{array}$ \\
\hline \multirow{3}{*}{ K $_{\text {ATP channel subunits }}$} & Kir6.1 & - & - & - & - & - & - \\
\cline { 2 - 9 } & Kir6.2 & - & + & + & + & + & + \\
\cline { 2 - 9 } & Sur1 & - & - & - & + & + & + \\
\cline { 2 - 9 } & Sur2 & - & - & - & + & + & + \\
\hline \multirow{2}{*}{ Cav channel subunits } & Cav1.2 & + & + & + & + & + & + \\
\cline { 2 - 9 } & Cav2.2 & + & + & + & + & + & + \\
\hline
\end{tabular}

Figure $1 \mathrm{~N}-43 / 5$ POMC phenotypic profiles. (A) Phase contrast micrograph of immortalized mouse N-43/5 cells. (B) RT-PCR and western blotting analysis (calcium channels) confirms that glucose-sensing machinery was expressed in a number of clonal hypothalamic cells expressing NPY and POMC. These include glucokinase; glucose transporters 1-4; ATP-sensitive $\mathrm{K}^{+}$channel subunits Kir 6.2, and Sur 1 and 2; and calcium channel subunits, Cav1.2 and Cav2.2.

(Invitrogen). Two hundred nanograms RNA of each cell line were used as a template for one-step RT-PCR using the Qiagen one-step RT-PCR kit according to the manufacturer's instructions (Qiagen). The primers were as follows: NPY, sense 5'TAG GTA ACA AGC GAA TGG G3' and anti-sense 5'ACA TGG AAG GGT CTT CAA GC3' (282 fragment); POMC: sense 5'ATG CCG AGA TTC TGC TAC AGT CG3' and anti-sense 5'TTC ATC TCC GTT GCC AGG AAA CAC3' (191 bp). The primer sequences for the glucose-sensing machinery are described in Table 1. 
Table 1 Primer sequences used in marker screening

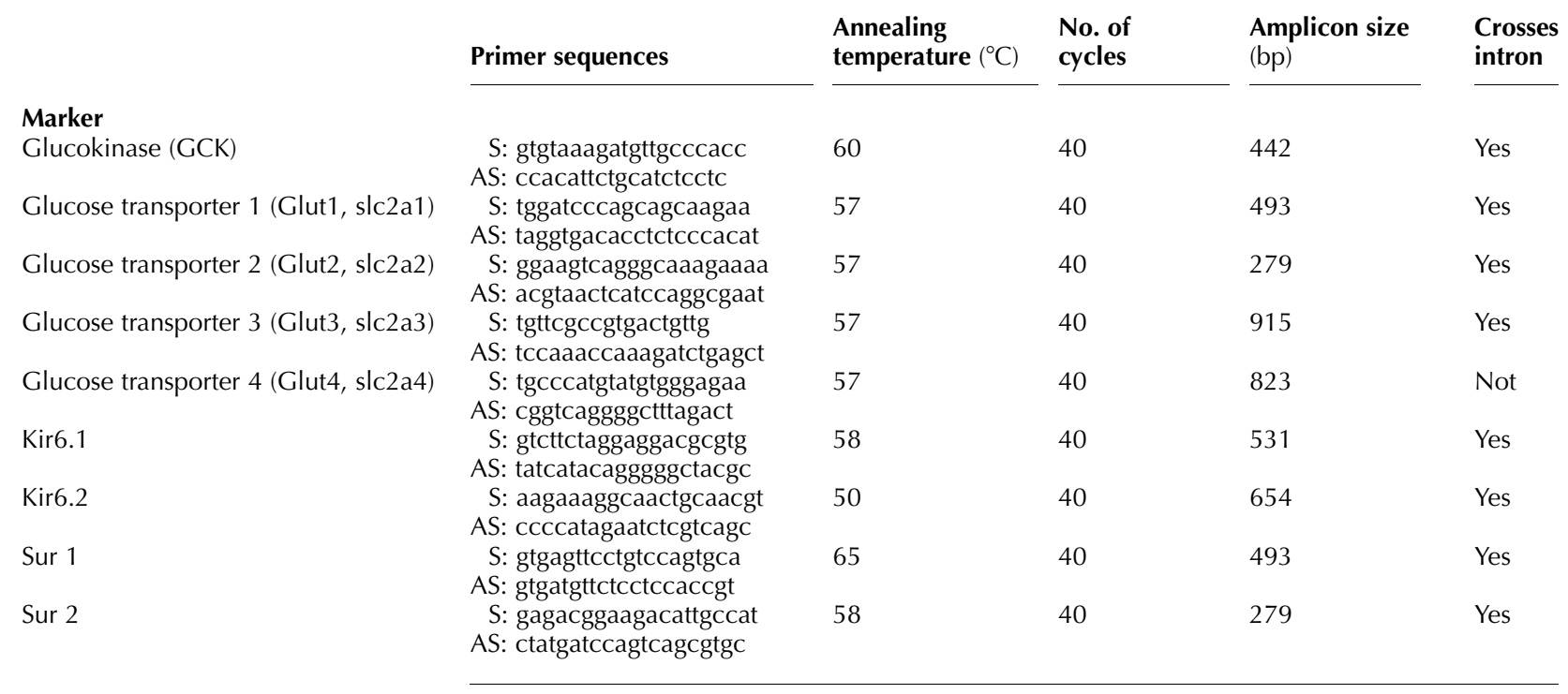

S, sense; AS, antisense.

Gene expression analysis using quantitative real-time $R T-P C R$

Total RNA from N-43/5 cells was isolated by the guanidinium thiocyanate-phenol-chloroform extraction method. First strand cDNA was synthesized from $2 \mu \mathrm{g}$ RNA in a total volume of $20 \mu \mathrm{l}$ using High archive cDNA kit (Applied Biosystems, Inc., Streetsville, ON, Canada). POMC real-time PCRs were performed using the POMC1 Taqman Gene Expression Assay (Applied Biosystems, Inc.), according to the manufacturer's instructions, and run on the Prism 7900 real-time PCR machine (Applied Biosystems, Inc.). Real-time PCR values were calculated by absolute quantity method and normalized to $\gamma$-actin mRNA levels at the corresponding time points. $\gamma$-Actin primer sequences are as follows: sense $5^{\prime} \mathrm{CTT}$ CCC CAC GCC ATC TTG3', and anti-sense 5'CCC GTT CAG TCA GAT CTT CAT3'.

\section{SDS-PAGE and western blot analysis}

Cell protein was prepared essentially as described previously (Cui et al. 2005). Cell protein was collected in $1 \times$ cell lysis buffer (Cell Signaling Technology, Inc., Danvers, MA, USA) with $1 \mathrm{mM}$ phenylmethylsulfonylfluoride. Forty micrograms of each cell protein were resolved on SDS-PAGE gels and blotted onto Hybond-C nitrocellulose membranes (Amersham Biosciences, Piscataway, NJ, USA). The resulting blot was blocked with 5\% skim milk in PBS containing $0 \cdot 1 \%$ Tween 20 , and incubated with primary antibody $(1: 1000)$ overnight at $4{ }^{\circ} \mathrm{C}$, and then with horseradish peroxidase-labeled secondary goat anti-rabbit antisera (Amersham Biosciences, \#NA934V) 1:5000 at room temperature for $1 \mathrm{~h}$. Protein was visualized using the ECL advance western blotting detection kit (Amersham Biosciences). Cav1.2 or Cav2.2 was purchased from Chemicon International,
Inc. (Temecula, CA, USA) and phospho-AMPK- $\alpha$ (Thr172), phospho-acetyl CoA carboxylase (ACC; Ser79), ACC, or AMPK- $\alpha$ subunit antibodies were from Cell Signaling Technology.

Fluorescent measurements of $\mathrm{Ca}^{2+}$ mobilization

For fluorescent measurements, the incubation and perfusion buffer had the following compositions (in $\mathrm{mM}$ ): $130 \mathrm{NaCl}$, $5 \mathrm{KCl}, 2 \mathrm{CaCl}_{2}, 1 \mathrm{MgCl}_{2}, 5 \mathrm{NaHCO}_{3}$, and $10 \mathrm{HEPES}$, pH 7•4. In selected experiments, to depolarize the cells, $50 \mathrm{mM} \mathrm{NaCl}$ were replaced with $50 \mathrm{mM} \mathrm{KCl}$. Cells, plated onto glass coverslips coated with poly-L-lysine, were loaded with $2 \mu \mathrm{M}$ Fluo-4 for $45 \mathrm{~min}$ in incubation buffer in the presence of $2 \mathrm{mM}$ glucose at $37{ }^{\circ} \mathrm{C}$ and $5 \% \mathrm{CO}_{2}-95 \%$ air. Fluorescent experiments were carried out using an Olympus BX51W1 fluorescent microscope fitted with $20 \times / 0.95$ water immersion objective and cooled CCD camera. For excitation, xenon lamp-based Delta Ram high-speed monochromator from Photon Technology International (PTI, Lawrenceville, NJ, USA) was used. For control of monochromator and video camera, as well as fluorescent imaging and collecting of data, the ImageMaster 3.0 software (PTI) was used. Coverslip with cells was transferred to an open chamber, placed on microscope stage, and perfused at a rate of $1 \mathrm{ml} / \mathrm{min}$. Experiments were performed at $36-37^{\circ} \mathrm{C}$ using TC-324B Heater Controller (Warner Instruments, Hamden, CT, USA). The fluorescence of Fluo-4 AM was excited at $480 \mathrm{~nm}$ and emission was measured with 525 bandpass filter using $505 \mathrm{~nm}$ beam splitter. The changes in intracellular $\mathrm{Ca}^{2+}\left(\left[\mathrm{Ca}^{2+}\right]_{i}\right)$ were calculated according to the equation

$\left[\mathrm{Ca}^{2+}\right]_{i}=K_{\mathrm{d}}\left(\frac{F-F_{\min }}{F-F_{\max }}\right)$, 
where $F$ is the measured fluorescence intensity, $F_{\min }$ and $F_{\max }$ are the fluorescence at $\mathrm{Ca}^{2+}$-free and -saturating conditions, and $K_{\mathrm{d}}$ is the dissociation constant of the indicator for $\mathrm{Ca}^{2+}(345 \mathrm{~nm})$. $\mathrm{Ca}^{2+}$-saturating and -free conditions were obtained by addition of $5 \mu \mathrm{M}$ ionomycin to cells incubated with $5 \mathrm{mM} \mathrm{Ca}^{2+}$, and by addition of $5 \mathrm{mM}$ EGTA to cells incubated in $\mathrm{Ca}^{2+}$-free medium.

\section{Statistical analysis}

Data were analyzed using one-way ANOVA by GraphPad Prism (GraphPad Software, Inc., San Diego, CA, USA) and statistical significance was determined using Tukey's multiple comparison tests or Student's $t$-test with $P<0 \cdot 05$.

\section{Results}

Expression of POMC and other hypothalamic markers in $\mathrm{N}-43 / 5$ neurons

We used a representative cell model from the cell lines that have been characterized in our laboratory (Fig. 1A). The cell line was specifically chosen as a representative neuronal cell model, as they expressed detectable levels of POMC (Fig. 1B). The mixed cell cultures were originally generated through dispersed whole hypothalamic primary cell culture; therefore, we cannot be certain of the exact region of origin without further characterization of other cellular markers. We analyzed the expression of an extensive list of neuropeptides, neuropeptide receptors, and enzymes associated with the synthesis of neurotransmitters in the $\mathrm{N}-43 / 5$ cells. We found that POMC and CART were expressed in N-43/5 cells, but NPY was not expressed at detectable levels, as expected. Receptor profiles were analyzed for the N-43/5 cells, and the neurons expressed receptors for estrogen receptors $\alpha$ and $\beta$, androgen, leptin, insulin, melanocortin concentrating hormone (MCH), melanocortin (MC4), glucocorticoid, and serotonin. The cells also expressed tyrosine hydroxylase, the rate-limiting enzyme in the synthesis of catecholamines, dopamine and norepinephrine, and dopamine transporter. They also exhibited evidence for $\gamma$-aminobutyric acid synthesis, through glutamate decarboxylase expression. The phenotypic profiles reflected by determination of over 100 markers in the two cell lines indicate that the most likely origin of these clonal cells was the arcuate nucleus of the hypothalamus.

\section{Analysis of functional glucose-sensing machinery in N-43/5 cells}

The pancreatic $\beta$-cell senses glucose through specific cellular proteins (Schuit et al. 2001). Treatment of $\beta$-cells with stimulatory concentrations of glucose resulted in an increase in the ATP:ADP ratio, thereby inhibition of ATP-sensitive potassium channels $\left(\mathrm{K}_{\mathrm{ATP}}\right)$, leading to depolarization of the plasma membrane and activation of voltage-dependent calcium channels (VDCC). These same mechanisms have been hypothesized to function in specific cell types from the hypothalamus. We therefore confirmed by either RT-PCR or western blotting that glucose-sensing machinery was expressed in a number of NPY-expressing and POMCexpressing cells, including N-43/5 cells (Fig. 1B). Glucose transporters 1-4, glucokinase (GK), the subunits of the ATPsensitive potassium channels $\left(\mathrm{K}_{\mathrm{ATP}}\right)$, and the subunits of the VDCC (Cav1.2, Cav2.2) were all expressed in the cell lines at highly detectable levels.

We tested the effect of high glucose $(16.7 \mathrm{mM})$, a specific $\mathrm{K}_{\text {ATP }}$ channel antagonist sulfonylurea tolbutamide $(250 \mu \mathrm{M})$, and depolarizing concentrations of potassium chloride $(\mathrm{KCl}$, $50 \mathrm{mM})$ on intracellular calcium mobilization $\left(\left[\mathrm{Ca}^{2+}\right]_{i}\right)$. We
A

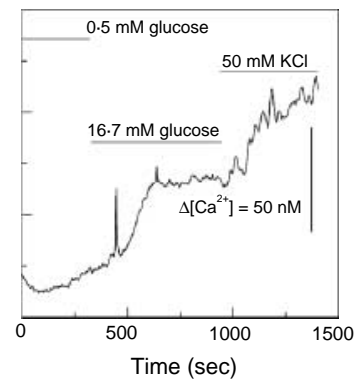

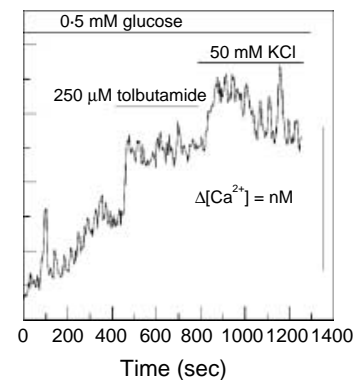

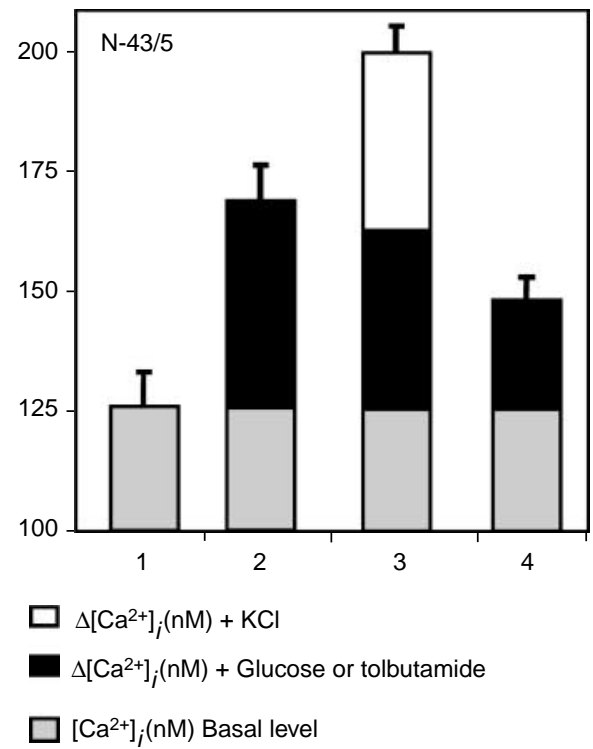

Figure 2 Calcium mobilization in N-43/5 POMC neurons. N-43/5 cells loaded with Fluo-4 AM were perfused with the various reagents indicated. (A) Representative result of time-dependent changes in $\left[\mathrm{Ca}^{2+}\right]_{i}$ in N-43/5 POMC neurons. Cells were perfused with $0.5 \mathrm{mM}$ glucose, then with $16.7 \mathrm{mM}$ glucose, followed by $50 \mathrm{mM} \mathrm{KCl}$ (left panel); cells were perfused with $0.5 \mathrm{mM}$ glucose, then with $250 \mu \mathrm{M}$ tolbutamide, followed by $50 \mathrm{mM} \mathrm{KCl}$ (right panel). (B) The mean values of $\left[\mathrm{Ca}^{2+}\right]_{i}$ changes in $\mathrm{N}-43 / 5$ POMC neurons after the indicated treatments. Lane 1, basal levels $(n=17)$; lane 2, with glucose added ( $n=9)$; lane 3 , with $\mathrm{KCl}$ added $(n=10)$; lane 4 , with tolbutamide added $(n=4)$. 
found that in $\mathrm{N}-43 / 5$ neurons, these stimuli evoked a rapid increase in $\left(\left[\mathrm{Ca}^{2+}\right]_{i}\right.$. The representative traces and quantification of the results from at least nine individual neurons for N-43/5 POMC cells are illustrated (Fig. 2A and B). All of the treatments (perfusion with high glucose, tolbutamide, or $\mathrm{KCl}$ ) presumably led to the depolarization of plasma membrane and activation of $\mathrm{Ca}^{2+}$ channels, and as a result, increased $\mathrm{Ca}^{2+}$ influx into the cells. This indicates that the neurons possess
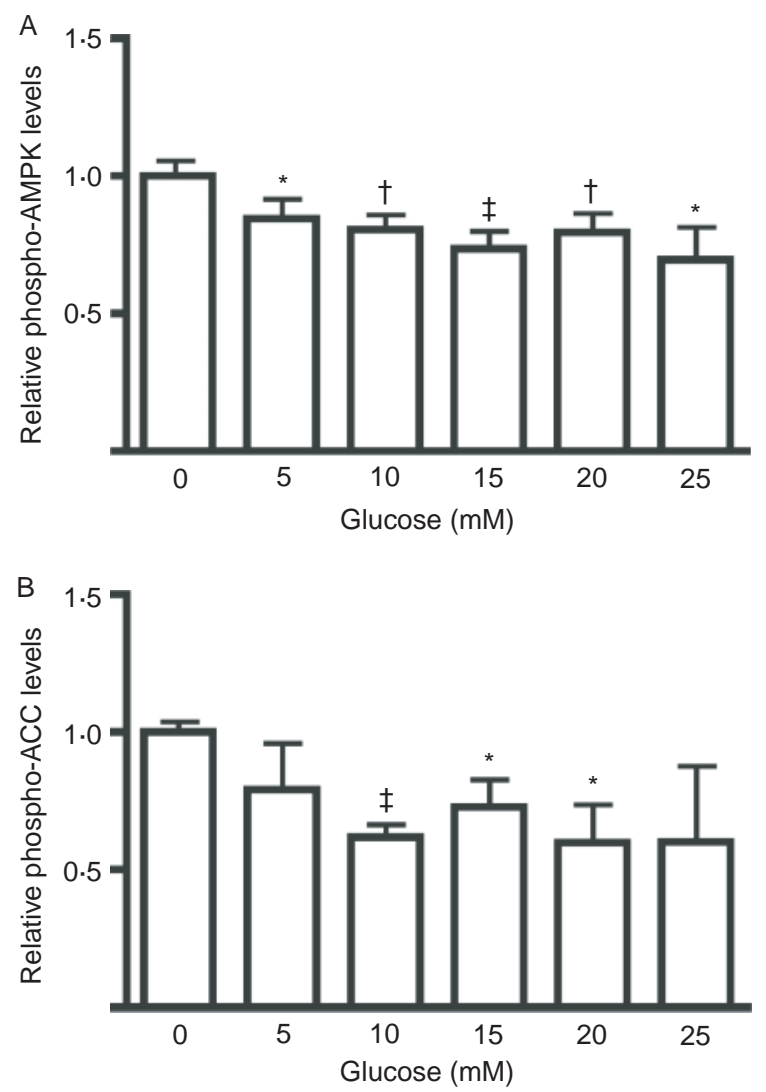

C

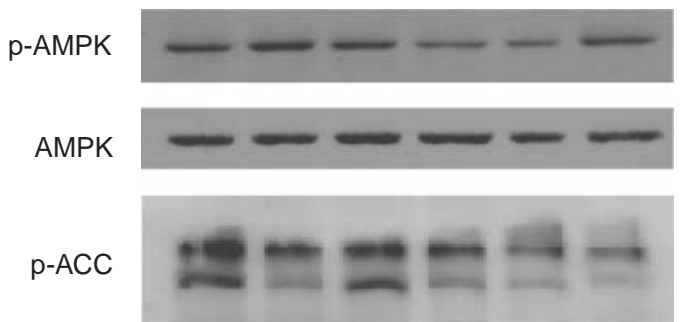

Figure 3 Glucose regulates AMPK and ACC activity in N-43/5 POMC neurons. N-43/5 POMC neurons were stimulated with or without glucose for the indicated concentrations for $0.5 \mathrm{~h}$. Cell lysates were examined by western blot with phospho-specific AMPK or ACC and normalized using total AMPK or ACC antibodies. The summary of all experiments performed $(n \geq 3)$ are presented in the respective graphs as means \pm S.E.M., indicated points significantly different $\left({ }^{*} P<0 \cdot 05,{ }^{\dagger} P<0 \cdot 01,{ }^{\ddagger} P<0 \cdot 001\right)$ compared with the untreated control; (A) pAMPK and (B) ACC. (C) Immunoblots shown are representative of an experiment performed at least thrice. functional ATP-sensitive potassium channels and are responsive to glucose through changes in calcium mobilization.

\section{Glucose effects on $A M P K$ and $A C C$}

To determine whether glucose affected cellular function, we analyzed AMPK activity due to its known role as a nutrient sensor in many divergent cell types. We utilized the N-43/5 cell model to analyze the effects of nutrient signals on AMPK activity. We exposed the cells to an increasing concentration of glucose for $30 \mathrm{~min}$ to determine changes in AMPK $\alpha$-subunit phosphorylation. Using a phospho-specific antibody against AMPK, we found that increasing glucose concentrations had a repressive effect on AMPK activity in the POMC cell line (Fig. 3A). Specifically, increasing glucose concentrations from 5 to $25 \mathrm{mM}$ significantly decreased AMPK activity in N-43/5 POMC neurons (Fig. $3 \mathrm{~A} ; 5 \mathrm{mM}$, $0 \cdot 84 \pm 0.07 ; 10 \mathrm{mM}, 0 \cdot 80 \pm 0 \cdot 05 ; 15 \mathrm{mM}, 0.73 \pm 0 \cdot 06$ $20 \mathrm{mM}, 0.79 \pm 0.06 ; 25 \mathrm{mM}, 0.69 \pm 0.12$; each $P<0.05$, $n=7-8$ ). To confirm the activity of AMPK in the N-43/5 neurons, we also measured the phosphorylation of ACC, a downstream substrate of pAMPK (Minokoshi et al. 2002, Yamashita et al. 2004, Targonsky et al. 2006). Decreased phosphorylation of ACC indicates increased activity leading to an increase in malonyl-CoA, a potential regulatory component of the energy-sensing system (Wolfgang \& Lane 2006). We found that pACC phosphorylation, as measured by the western blot analysis using a phospho-specific antibody to ACC, mimicked that of pAMPK as expected (Fig. 3B). pACC phosphorylation was normalized to both total ACC and $\beta$-actin to confirm, since the total ACC antibody reactivity was not optimal.

\section{Regulation of POMC $m R N A$ expression by glucose}

In order to define potential downstream effector molecules regulated by glucose, we decided to examine POMC transcription. We found that $P O M C$ gene expression in $\mathrm{N}-43 / 5$ cells significantly increased at 4 h with $2.8 \mathrm{mM}$ glucose $(2 \cdot 31 \pm 0 \cdot 57 ; P<0 \cdot 05, n=4)$, with an increasing trend from 2 to $4 \mathrm{~h}$ (Fig. 4A). Stimulation with $16.7 \mathrm{mM}$ glucose also significantly increased $P O M C$ gene expression at $4 \mathrm{~h}$ (Fig. 4B; $3 \cdot 22 \pm 0 \cdot 91 ; P<0 \cdot 05, n=3)$. These results not only substantiate these neurons as appropriate glucose-sensing models, but also indicate that glucose alone can have a major effect on the synthesis of neuropeptides directly involved in energy homeostasis.

\section{Leptin effects on AMPK activity}

Neurons are typically exposed to combinations of nutrient signals, and whether the effects are additive is not yet known. Using the results from the initial glucose experiments, we decided to analyze the effects of leptin $(1 \mathrm{ng} / \mathrm{ml}$ or $0.062 \mathrm{nM})$ in the medium that contained $5,25 \mathrm{mM}$, or no glucose, as these were the most relevant concentrations from the initial AMPK 

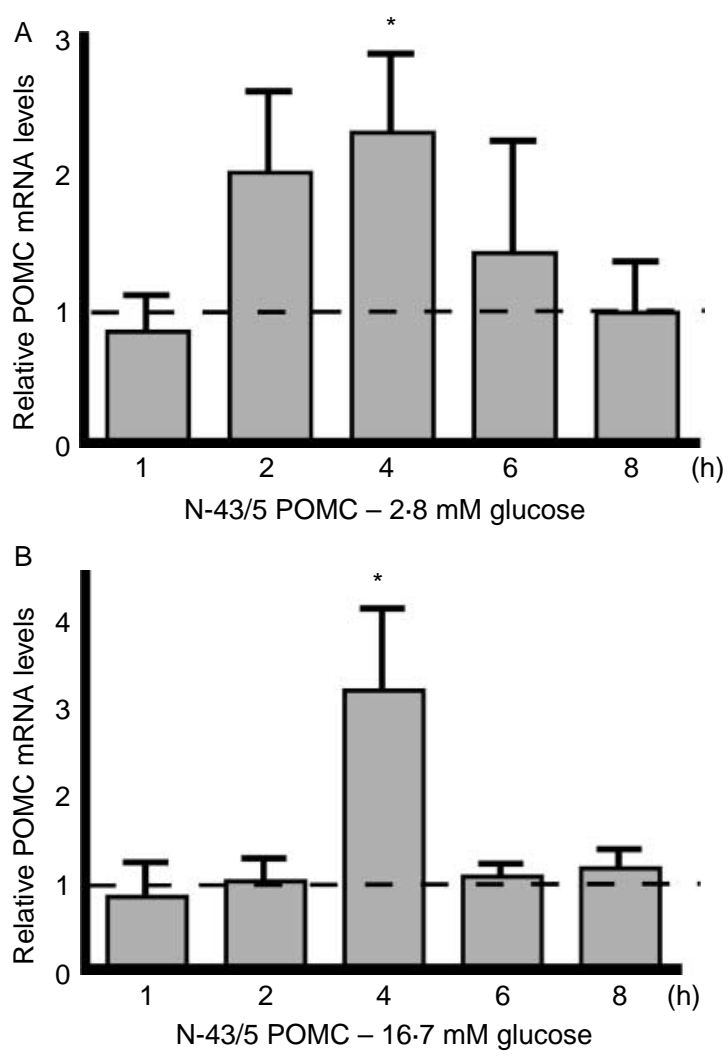

Figure 4 Glucose regulates $P O M C$ gene expression in $\mathrm{N}-43 / 5$ $P O M C$ neurons. Analysis of $P O M C$ gene expression following $2 \cdot 8$ and $16.7 \mathrm{mM}$ glucose stimulation. Total RNA was isolated at the indicated time points. Real-time RT-PCR was performed for POMC. mRNA levels were normalized to $\gamma$-actin mRNA levels. Only changes with treatments are represented in the histograms, whereas time-matched control values for each time point (vehicle alone), set to 1 , are indicated by the dashed lines. Values are expressed as mean \pm s.E.M. with statistical significance, $* P<0 \cdot 05(n=3-4)$. (A) With $2.8 \mathrm{mM}$ glucose, POMC mRNA increased at $4 \mathrm{~h}$. (B) With $16 \cdot 7 \mathrm{mM}$ glucose, POMC mRNA also significantly increased at $4 \mathrm{~h}$.

experiments. We found that in the absence of glucose, leptin suppressed AMPK activity in POMC neurons when compared with glucose-matched controls (Fig. 5A; 0.52 $\pm 0 \cdot 09 ; P<0 \cdot 05$, $n=4)$. At low glucose, AMPK activity was marginally suppressed by leptin in the POMC neurons (Fig. 5A; 0.73 \pm $0 \cdot 11 ; P<0 \cdot 05, n=5$ ), whereas the addition of leptin did not change the basal effect of $25 \mathrm{mM}$ glucose alone.

\section{Insulin effects on AMPK activity}

Using the same parameters, we analyzed the effect of $100 \mathrm{nM}$ insulin on AMPK activity in the N-43/5 cells. There was no change in phospho-AMPK levels in response to insulin stimulation in the cell line (Fig. 5B) in the absence of glucose in the medium. Similarly, at high glucose levels, there was no change in AMPK activity with insulin in N-43/5 POMC
A

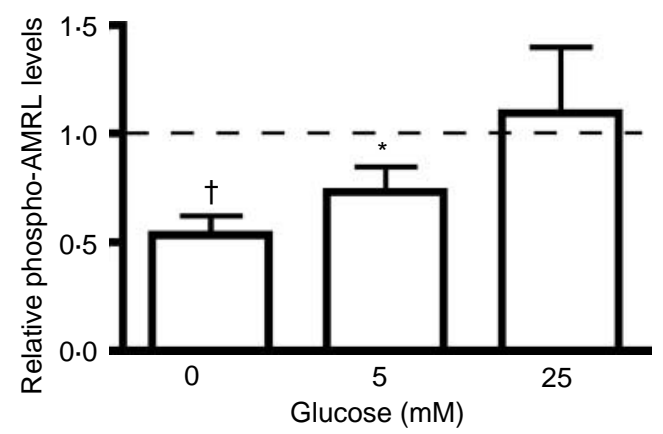

$\mathrm{N}-43 / 5$ POMC with Leptin

B

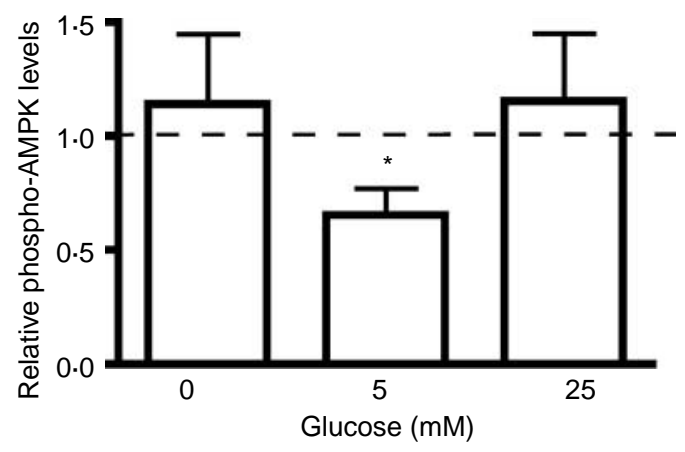

$\mathrm{N}-43 / 5$ POMC with insulin
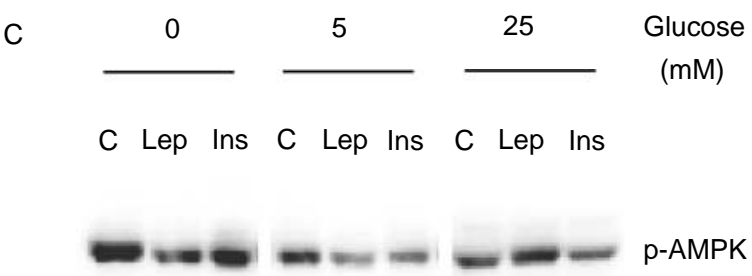

Figure 5 Leptin and insulin regulate AMPK activity in N-43/5 POMC neurons. $\mathrm{N}-43 / 5$ POMC neurons were stimulated with or without $(A)$ leptin $(1 \mathrm{ng} / \mathrm{ml}$ or $0.062 \mathrm{nM})$ or $(B)$ insulin $(100 \mathrm{nM})$ in combination with 5 or $25 \mathrm{mM}$ glucose for $0.5 \mathrm{~h}$. Cell lysates were examined by western blot with phospho-specific AMPK and total AMPK antibodies. The summary of all experiments performed $(n \geq 3)$ are presented in the respective graphs as means \pm S.E.M., indicated points significantly different $\left({ }^{*} P<0 \cdot 05,{ }^{\dagger} P<0 \cdot 001\right)$ compared with the untreated glucosematched control $(0,5$, and $25 \mathrm{mM}$ glucose alone). Only changes with treatments are represented in the histograms, whereas time-matched control values for each glucose concentration, set to 1 , are indicated by the dashed lines. (C) Immunoblot shown is representative of an experiment performed at least thrice. Lep, leptin; Ins, insulin; C, control.

neurons. However, at low glucose levels, there was a significant decrease in AMPK activity with insulin treatment in the POMC neurons (Fig. 5B; 0.65 $\pm 0 \cdot 12 ; P<0 \cdot 05, n=4$ ). 


\section{Discussion}

Recent studies show that glucose-responsive hypothalamic neurons may use the same molecular mechanisms as the pancreatic $\beta$-cells to recognize and respond to extracellular glucose changes. As in the pancreatic $\beta$-cell, the ATPsensitive potassium $\left(\mathrm{K}_{\mathrm{ATP}}\right)$ channel is an important component of glucose sensing in glucose-excitatory (also referred to as glucose-responsive) neurons (Ashford et al. 1990a,b, Miki et al. 2001, Minami et al. 2004), found predominantly in the ventromedial region of the hypothalamus, containing both the arcuate and ventromedial nuclei (Routh 2002). The mere presence of the $\mathrm{K}_{\mathrm{ATP}}$ channel does not necessarily mean that a given neuron will be glucose sensing, since this channel is widely expressed throughout the brain. Furthermore, glucose-inhibited (also called glucose-sensitive) neurons most likely do not use the $\mathrm{K}_{\mathrm{ATP}}$ channel to sense glucose (Kang et al. 2004, Levin et al. 2004). Thus, other regulatory components are also likely involved in neuronal glucose sensing. The control of both glycolysis and glucose transport has been proposed as a regulator of $\beta$-cell glucose sensing. In the pancreas, GK (also called hexokinase IV) regulates glycolytic flux and intracellular ATP production in both $\beta$ - and $\alpha$-cells and is a primary regulator of ATP production, $\mathrm{K}_{\mathrm{ATP}}$ channel activity, and insulin secretion in the $\beta$-cells (Schuit et al. 2001). A large body of evidence also indicates that GK is a critical component of glucose sensing in neurons as well (Levin et al. 2004). GLUT2 has also been proposed as a regulator of $\beta$-cell glucose sensing (Thorens 2001), and some neurons do express GLUT2 (Kang et al. 2004). GLUT4 is a good candidate to regulate neuronal glucose sensing due to its localization in regions associated with glucose sensing, co-expression with the insulin receptor, and its optimal $K_{\mathrm{m}}$ for glucose within the physiological range; however, it is thought that the majority of glucose-sensing neurons use GLUT3 as their major glucose transporter (Kang et al. 2004). We have demonstrated the expression of components of the same system in our N-43/5 POMC-expressing hypothalamic cells, including glucose transporters $1-4$, GK, the subunits of the $\mathrm{K}_{\mathrm{ATP}}$ channel, and the subunits of the voltage-dependent calcium channels.

The activity of NPY and POMC cells is oppositely regulated by body energy status, and may directly respond to altered glucose availability, as glucose is the main metabolic fuel of the brain. To investigate the role of hypothalamic neurons in glucose homeostasis, it is important to define physiologic levels for extracellular glucose in the brain. As a rule, brain glucose levels are approximately $10-30 \%$ of that in the plasma (Routh 2002, de Vries et al. 2003). Thus, plasma glucose levels of 5-8 $\mathrm{mM}$ correspond to brain glucose levels of about 1-2.5 mM, which is considered to be euglycemic (Silver \& Erecinska 1998). During insulin-induced hypoglycemia (plasma glucose 2-3 mM), brain glucose levels were approximately $0.5 \mathrm{mM}$. However, refeeding (15-17 $\mathrm{mM}$ plasma glucose levels) resulted in brain glucose levels of $4.5 \mathrm{mM}$
(Silver \& Erecinska 1994). Brain glucose levels reach a $5 \mathrm{mM}$ threshold with plasma hyperglycemia (Routh 2002). However, if the neurons are in or near a region lacking a blood-brain barrier, such as in the cells surrounding the third ventricle (including cells from the arcuate nucleus), brain glucose levels may approximate plasma glucose levels. Neurons in these regions may be normally exposed to higher levels of extracellular glucose in some pathological circumstances, but unlikely to be exposed to extracellular glucose levels above $5 \mathrm{mM}$ under physiologic conditions (Routh 2002).

Emerging evidence indicates that AMPK may be a general regulator of energy homeostasis. AMPK activity in the hypothalamus is increased by fasting and normalizes upon refeeding in mice, which may correlate to changing levels of glucose and insulin (Minokoshi et al. 2004). Hypothalamic AMPK activity is acutely affected by the availability of specific nutrients, and using whole hypothalamic extracts or from specific regions of the brain, it has been shown that glucose directly regulates AMPK activity (Andersson et al. 2004, Kim et al. 2004, Minokoshi et al. 2004). Specifically, i.c.v. administration of glucose decreases hypothalamic AMPK activity (Minokoshi et al. 2004). Leptin and insulin produce a similar decrease in overall AMPK activity, while ghrelin, an orexigenic gut peptide, appears to increase it (Andersson et al. 2004, Minokoshi et al. 2004). Leptin has been shown to specifically affect neurons from the arcuate and paraventricular nuclei of the hypothalamus, indicating that the melanocortin neurons may be involved in this process. As such, the melanocortin receptor agonist MT II decreases, whereas AgRP increases phospho-AMPK levels (Minokoshi et al. 2004). Other known modulators of AMPK activity include C57, a fatty acid synthase (FAS) inhibitor, systemic hypoglycemia, streptozotocin-induced diabetes mellitus, and $\alpha$-lipoic acid (Carling 2005). Therefore, we can speculate from this information that overall AMPK activity is decreased by anorexigenic factors and stimulated by orexigenic factors. A recent study using metformin, an anti-diabetic drug linked to weight loss, demonstrates that low glucose $(1 \mathrm{mM})$ causes an increase in AMPK activity, resulting in a decrease in NPY gene expression. However, POMC gene expression was inhibited at low glucose, but was not linked to a change in AMPK activity in primary rat hypothalamic neurons (Chau-Van et al. 2006). In our $\mathrm{N}-43 / 5$ cell model, we found that AMPK activity was decreased (at higher levels of glucose), resulting in an increase in POMC gene expression. Two cell lines that express AgRP were previously used to study AMPK activity, a neuroblastoma line N1E-115 and a gonadotropin-releasing hormone $(\mathrm{GnRH})$ secreting cell model GT1-7 (Lee et al. 2005). In these cells, they found that increasing glucose to $25 \mathrm{mM}$ decreased AMPK activity. Interestingly, AgRP expression decreased with increasing glucose concentrations. The mouse N1E-115 neuroblastoma cells, derived from a spontaneous tumor in a region of the spinal cord, are not likely representative of arcuate AgRP neurons due to the fact that they are not from the hypothalamus or central nervous system (CNS) and do not 
co-express NPY, and the GT1-7 cells express GnRH and are a well-defined model of the GnRH neuron, which does not typically co-express AgRP or NPY. Therefore, it would be optimal to use cell models derived from the hypothalamus that express appropriate cell markers related to energy homeostasis. Our studies with the N-43/5 POMC neurons indicate that the levels of glucose available to the cell may affect AMPK responses to peripheral signals, particularly leptin and insulin.

While we have focused on a specific cell type from the hypothalamus, it is important to recognize that AMPK also has substantial effects on peripheral tissues, such as the maintenance of glucose homeostasis (Kahn et al. 2005). Thus, it has been suggested that AMPK activators may be used for the treatment of diabetes mellitus, as it stimulates glucose uptake in skeletal muscle and inhibits liver glucose synthesis (Musi \& Goodyear 2002). The findings from the hypothalamus may, however, counteract these positive effects by increasing food intake. Therefore, it would be in our best interest to understand the specific cell types that are using AMPK to achieve changes in neuropeptide secretion, in order to specifically target therapeutic intervention to the appropriate cell and tissue. Our findings suggest that individual neuronal cell types, such as the POMC neuron, may indeed respond to peripheral signals differentially, and that the AMPK response may depend on glucose levels as well. The complexity of the hypothalamic architecture and the number of neuronal cell types involved in the regulation of energy homeostasis make these studies a daunting task. However, we suggest that this is a necessary exercise in order to understand the specific changes at the level of neuropeptide synthesis and secretion, the ultimate downstream effectors of overall changes in glucose concentrations and AMPK activity.

\section{Acknowledgements}

We thank Elisha Targonsky for technical advice. Thanks to members of the Belsham Laboratory for critical reading of the manuscript. This work was supported by the Canadian Institutes for Health Research (CIHR) and the Canadian Diabetes Association. D D B holds a Canada Research Chair in Neuroendocrinology and is a Canada Foundation for Innovation Researcher. M B W is a CIHR Investigator. The authors declare that there is no conflict of interest that would prejudice the impartiality of this scientific work.

\section{References}

Anand BK, Chhina GS, Sharma KN, Dua S \& Singh B 1964 Activity of single neurons in the hypothalamic feeding centers: effect of glucose. American Journal of Physiology 207 1146-1154.

Andersson U, Filipsson K, Abbott CR, Woods A, Smith K, Bloom SR, Carling D \& Small CJ 2004 AMP-activated protein kinase plays a role in the control of food intake. Journal of Biological Chemistry 279 12005-12008.
Ashford ML, Boden PR \& Treherne JM 1990a Glucose-induced excitation of hypothalamic neurones is mediated by ATP-sensitive $\mathrm{K}+$ channels. Pflugers Archiv 415 479-483.

Ashford ML, Boden PR \& Treherne JM $1990 b$ Tolbutamide excites rat glucoreceptive ventromedial hypothalamic neurones by indirect inhibition of ATP-K ${ }^{+}$channels. British Journal of Pharmacology 101 531-540.

Belsham DD, Cai F, Cui H, Smukler SR, Salapatek AMF \& Shkreta L 2004 Generation of a phenotypic array of hypothalamic neuronal cell models to study complex neuroendocrine disorders. Endocrinology 145 393-400.

Breen TL, Conwell IM \& Wardlaw SL 2005 Effects of fasting, leptin, and insulin on AGRP and POMC peptide release in the hypothalamus. Brain Research 1032 141-148.

Burdakov D, Luckman SM \& Verkhratsky A 2005 Glucose-sensing neurons of the hypothalamus. Philosophical Transactions of the Royal Society of London. Series B, Biological Sciences 360 2227-2235.

Carling D 2005 AMP-activated protein kinase: balancing the scales. Biochimie 87 87-91.

Chau-Van C, Gamba M, Salvi R, Gaillard R \& Pralong F 2006 Metformin inhibits AMPK activation and prevents increases in NPY expression in cultured hypothalamic neurons. Endocrinology. In press.

Cui H, Cai F \& Belsham DD 2005 Anorexigenic hormones leptin, insulin, and a-melanocyte stimulating hormone directly induce neurotensin (NT) gene expression in novel NT-expressing cell models. Journal of Neuroscience 25 9497-9506.

Hardie DG 2004 The AMP-activated protein kinase pathway - new players upstream and downstream. Journal of Cell Science 117 5479-5487.

Kahn BB, Alquier T, Carling D \& Hardie DG 2005 AMP-activated protein kinase: ancient energy gauge provides clues to modern understanding of metabolism. Cell Metabolism 1 15-25.

Kang L, Routh VH, Kuzhikandathil EV, Gaspers LD \& Levin BE 2004 Physiological and molecular characteristics of rat hypothalamic ventromedial nucleus glucosensing neurons. Diabetes 53 549-559.

Kim MS \& Lee KU 2005 Role of hypothalamic 5'-AMP-activated protein kinase in the regulation of food intake and energy homeostasis. Journal of Molecular Medicine 83 514-520.

Kim MS, Park JY, Namkoong C, Jang PG, Ryu JW, Song HS, Yun JY, Namgoong IS, Ha J, Park IS et al. 2004 Anti-obesity effects of alpha-lipoic acid mediated by suppression of hypothalamic AMP-activated protein kinase. Nature Medicine 10 727-733.

Lee K, Li B, Xi X, Suh Y \& Martin RJ 2005 Role of neuronal energy status in the regulation of adenosine $5^{\prime}$-monophosphate-activated protein kinase, orexigenic neuropeptides expression, and feeding behavior. Endocrinology $1463-10$.

Levin BE, Routh VH, Kang L, Sanders NM \& Dunn-Meynell AA 2004 Neuronal glucosensing: what do we know after 50 years? Diabetes $\mathbf{5 3}$ 2521-2528.

Miki T, Liss B, Minami K, Shiuchi T, Saraya A, Kashima Y, Horiuchi M, Ashcroft F, Minokoshi Y, Roeper J et al. 2001 ATP-sensitive $\mathrm{K}^{+}$channels in the hypothalamus are essential for the maintenance of glucose homeostasis. Nature Neuroscience 4 507-512.

Minami K, Miki T, Kadowaki T \& Seino S 2004 Roles of ATP-sensitive K ${ }^{+}$ channels as metabolic sensors: studies of Kir6 $\times$ null mice. Diabetes $\mathbf{5 3}$ S176-S180.

Minokoshi Y, Kim YB, Peroni OD, Fryer LG, Muller C, Carling D \& Kahn BB 2002 Leptin stimulates fatty-acid oxidation by activating AMP-activated protein kinase. Nature 415 339-343.

Minokoshi Y, Alquier T, Furukawa N, Kim YB, Lee A, Xue B, Mu J, Foufelle F, Ferre P, Birnbaum MJ et al. 2004 AMP-kinase regulates food intake by responding to hormonal and nutrient signals in the hypothalamus. Nature 428 569-574.

Musi N \& Goodyear LJ 2002 Targeting the AMP-activated protein kinase for the treatment of type 2 diabetes. Current Drug Targets. Immune, Endocrine and Metabolic Disorders 2 119-127.

Niswender KD \& Schwartz MW 2003 Insulin and leptin revisited: adiposity signals with overlapping physiological and intracellular signaling capabilities. Frontiers in Neuroendocrinology $241-10$. 
Oomura Y, Kimura K, Ooyama H, Maeno T, Iki M \& Kuniyoshi M 1964 Reciprocal activities of the ventromedial and lateral hypothalamic areas of cats. Science 143 484-485.

Routh VH 2002 Glucose-sensing neurons: are they physiologically relevant? Physiology and Behavior 76 403-413.

Schuit FC, Huypens P, Heimberg H \& Pipeleers DG 2001 Glucose sensing in pancreatic beta-cells: a model for the study of other glucose-regulated cells in gut, pancreas, and hypothalamus. Diabetes $501-11$.

Schwartz MW, Woods SC, Porte DJ, Seeley RJ \& Baskin DG 2000 Central nervous system control of food intake. Nature 404 661-671.

Silver IA \& Erecinska M 1994 Extracellular glucose concentration in mammalian brain: continuous monitoring of changes during increased neuronal activity and upon limitation in oxygen supply in normo-, hypo-, and hyperglycemic animals. Journal of Neuroscience 14 5068-5076.

Silver IA \& Erecinska M 1998 Glucose-induced intracellular ion changes in sugar-sensitive hypothalamic neurons. Journal of Neurophysiology $\mathbf{7 9}$ 1733-1745.

Steinberg GR, Watt MJ, Fam BC, Proietto J, Andrikopoulos S, Allen AM, Febbraio MA \& Kemp BE 2006 Ciliary neurotrophic factor suppresses hypothalamic AMP-kinase signaling in leptin-resistant obese mice. Endocrinology 147 3906-3914.

Targonsky ED, Dai F, Koshkin V, Karaman GT, Gyulkhandanyan AV, Zhang Y, Chan CB \& Wheeler MB 2006 alpha-Lipoic acid regulates AMP-activated protein kinase and inhibits insulin secretion from beta cells. Diabetologia 49 $1587-1598$.

Thorens B 2001 GLUT2 in pancreatic and extra-pancreatic gluco-detection (review). Molecular Membrane Biology 18 265-273.
Titolo D, Cai F \& Belsham DD 2006 Coordinate regulation of neuropeptide $\mathrm{Y}$ and agouti-related peptide gene expression by estrogen depends on the ratio of estrogen receptor (ER) alpha to ERbeta in clonal hypothalamic neurons. Molecular Endocrinology 20 2080-2092.

de Vries MG, Arseneau LM, Lawson ME \& Beverly JL 2003 Extracellular glucose in rat ventromedial hypothalamus during acute and recurrent hypoglycemia. Diabetes $\mathbf{5 2}$ 2767-2773.

Wang R, Liu X, Hentges ST, Dunn-Meynell AA, Levin BE, Wang W \& Routh VH 2004 The regulation of glucose-excited neurons in the hypothalamic arcuate nucleus by glucose and feeding-relevant peptides. Diabetes 53 1959-1965.

Wolfgang MJ \& Lane MD 2006 The role of hypothalamic Malonyl-CoA in energy homeostasis. Journal of Biological Chemistry 281 37265-37269.

Yamashita T, Eto K, Okazaki Y, Yamashita S, Yamauchi T, Sekine N, Nagai R, Noda M \& Kadowaki T 2004 Role of uncoupling protein-2 up-regulation and triglyceride accumulation in impaired glucose-stimulated insulin secretion in a beta-cell lipotoxicity model overexpressing sterol regulatory element-binding protein-1c. Endocrinology 145 3566-3577.

Zhang Y, Proenca R, Maffei M, Barone M, Leopold L \& Friedman JM 1994 Positional cloning of the mouse obese gene and its human homologue. Nature 372 425-432.

\section{Received in final form 20 December 2006}

Accepted 21 December 2006

Made available online as an Accepted Preprint 3 January 2007 